\title{
Neck pain and disability: a cross-sectional survey of the demographic and clinical characteristics of neck pain seen in a rheumatology clinic
}

\author{
Frank AO MBBS, FRCP ${ }^{1}$, De Souza LH PhD, FCSP ${ }^{2 a}$, Frank CA ${ }^{2 b}$ \\ 1. Consultant Physician \\ Departments of Rehabilitation Medicine and Rheumatology \\ Arthritis Centre \\ Northwick Park Hospital and Institute of Medical Research \\ HARROW \\ HA1 3UJ \\ UK
}

Tel: (0044) 0208869 2102; fax: 0208426 4358;

Email: andrew.frank1@btinternet.com

2. a. Professor of Rehabilitation and Head of Department, b. Research Assistant Centre for Research in Rehabilitation

Dept of Health and Social Care

Brunel University

Osterley Campus

ISLEWORTH

Middlesex

TW7 5DU

UK

Tel: (0044) 02088910121 x 2527; fax: 0208847 2030;

Email: lorraine.desouza@brunel.ac.uk

Key words:- neck pain; comorbidity; disability; sickness absence; Northwick Park Neck Pain Questionnaire.

Word count 4301 excl summary

Correspondence to Dr Andrew Frank

Conflict of Interest: Dr Frank is a Medical Adviser to Kynixa Ltd 


\section{Summary}

This hospital-based cross-sectional cohort study examines the clinical and demographic features of neck pain, disability (using the Northwick Park neck pain Questionnaire) and relationships to handicap in employment.

Of 173 consecutive referrals to a rheumatology clinic with neck pain, 70\% had neck/arm pain without neurological involvement; $13 \%$ other conditions, $11 \%$ nerve involvement and 5\% other spinal pain. 141 patients (mean age 50y) had mechanical or degenerative neck pain of which $13 \%$ was probably work related and $13 \%$ was trauma-related. 44 had taken sickness absence for an average of 30 weeks. Comorbidities were frequent (lumbar pain 51\%).

Those in work were significantly less disabled than those not working $(\mathrm{p}=0.001)$ and those off sick $(\mathrm{p}<0.01)$. Those reporting sleep disturbance, tearfulness and crying were significantly more disabled $(\mathrm{p}=0.0001)$ than those who did not.

Neck pain in secondary care is complicated by physical and emotional comorbidities. Comprehensive management requires a biopsychosocial model of care. 


\section{Introduction}

Neck pain is the 'poor cousin of back pain' ${ }^{1}$ receiving much less attention by way of research. ${ }^{1}$ It is estimated to affect up to $40 \%$ of the population over 1 year, ${ }^{2-3}$ with an annual incidence of $18 \% .{ }^{4}$ Lifetime prevalence may be as high as $67 \% .{ }^{5}$ It is the third most reported musculoskeletal pain in the Netherlands; ${ }^{6}$ and may persist over 10 years. ${ }^{7}$ It has been estimated that neck pain disables $4.6 \%$ of the adult population of Saskatchewan. ${ }^{5}$

Patients are usually managed in primary care, ${ }^{3}$ but are referred to hospital departments of physiotherapy, rheumatology and orthopaedics for imaging and neurological investigation and therapy. Unlike low back pain, there are no accepted national guidelines for the classification or management of neck pain, although guidelines for selected physical therapy interventions have been published. ${ }^{8}$

Psychological distress is common in neck pain as in other chronic pain states, ${ }^{9,10}$ and its evaluation may be critical to the overall management of the individual. In a working population, occupation is a well-recognised cause of neck and upper limb pain ${ }^{2}$ and has important implications for patient management. ${ }^{11}$ For those with occupationally related neck pain, suggestions for management have been published. ${ }^{11}$ It is unclear to what extent sickness absence may be related to neck pain in the UK. However it is known that musculo-skeletal problems are the second commonest reason for needing Incapacity Benefits in the $\mathrm{UK}^{12}$ and the commonest reason for long-term sickness absence in manual workers. ${ }^{13}$ 
Little work is available that has investigated neck pain referred for management in secondary care. It is unclear what proportions of such patients have an underlying systemic illness, may require surgery or conservative management. This crosssectional study examines the clinical, demographic and physical information gained by systematic examination and structured questionnaires in a consecutive cohort of patients referred to a rheumatology service with “neck pain”, or symptoms derived from the neck. The aim was to characterise the neck impairment, physical disability and their relationships to demographic information and employment status. Consequently this study reports a consecutive cohort of patients referred to a district hospital rheumatology service with referral letters suggestive of a neck problem. It further explores the nature of neck-induced disability to determine how the management of neck pain could be improved.

\section{Methods}

All patients referred to a district hospital department of Rheumatology (by general practitioners or hospital doctors) with neck-related issues, as determined by a consultant rheumatologist, were seen in a neck pain clinic. There was no age limit although children would normally be seen in the Paediatric Department. One hundred and seventy two consecutive National Health Service patients and 1 private patient were seen and assessed during 1996, totalling 173 subjects.

One hundred and forty one patients were found to suffer from neck pain thought to derive from a mechanical or degenerative musculo-skeletal condition. Other diagnoses presenting as a neck problem are given in Table 1. 
Data collected comprised of clinical, demographic (including postcode) and occupational details obtained using a purpose-designed proforma. A routine physical examination was performed with radiological examinations if needed. Social class was derived from the current or previous occupation. ${ }^{16}$ Causes for the pain were documented as due to road traffic accidents, other trauma, occupationally related or idiopathic. Patients were categorised as acute, acute on chronic and chronic as has been described previously. ${ }^{17}$

Subjects were asked their country of birth to give some indication of ethnic background. ${ }^{15}$ The total and episode duration of pain were derived as described previously. $^{17}$

Clinical pattern was derived from the assessment in clinic, including further investigations where needed e.g. MRI scanning. Six groups were modelled on those of Spitzer et $\mathrm{al}^{18}$ and the categories modified for cervical pain as follows: -

1 - Neck pain including trapezius \& interscapular pain

2 - Arm pain / paraesthesiae / numbness

3 - Probable root compression

4 - Confirmed root compression with imaging

5 - Cord compression

6 - Other 
Functional disability was assessed using the Northwick Park Neck Pain Questionnaire (NPQ), ${ }^{19}$ which is widely seen to be valid and reliable, ${ }^{20}$ although it does not cover emotional and some social issues. ${ }^{21}$ As some subjects did not drive, the items 1-8 were scored by adding the scores of the individual sections. The driving section was scored separately.

Individual's work status was classified into the following groups: - employed and working, employed but off sick, self-employed, not working due to spinal disability, unemployed, housewives, retired and other. Data were collected concerning sickness absence: -

- currently 'off sick'

- $\quad$ working but 'off sick' during the current episode of pain

- 'off sick’ during any previous episode of pain

- 'off sick' - total duration of sick leave at any time

For those whose neck pain might relate to occupation (either as causal or aggravating factors), details of their occupation were obtained and categorised retrospectively into sitting, standing, lifting, or other potential aggravating factors.

Tearfulness and sleep disturbance questions were included in the clinical interview (Appendix). Additional diagnostic data were collected at assessment and at follow-up by further tests when clinically indicated to confirm the clinical pattern. Patients were asked about comorbidities and where they experienced pain (Appendix). 
Where appropriate, comparisons are made between this sample of patients presenting with neck pain with a similar cohort reported from this service presenting with low back pain. $^{17}$

Analytical methods

Descriptive statistics were used to characterise the group data. Analysis of demographic data was performed using appropriate parametric or non-parametric statistics. Sub-group analysis was carried out using two-sampled t-tests for interval and ratio data and Mann-Whitney tests for ordinal data. Spearman's rank correlation coefficient was used to determine significant relationships. All analysis was carried out using Microsoft Excel for Windows 1997, or SPSS for Windows Version 9.

The study was approved by Harrow Research Ethics Committee.

\section{RESULTS}

\section{Subjects}

Data were collected on all 141 subjects with mechanical or degenerative neck pain who comprise the sample. Their mean age was 49.5 (sd 14.8, median 49, range 23-88) years, with no differences between men and women. Ten patients were aged 65-74 and 12 were aged 75 or over. The majority were referred from primary care (87\%), with only $13 \%$ being referred from other consultants, almost exclusively orthopaedic 
colleagues. Postcode analysis showed that 147 (86\%) came from the London boroughs of Brent and Harrow and a further 22 (13\%) came from adjacent boroughs.

Patients were classified by the nature of the neck pain into: -

$>$ Post-traumatic $(\mathrm{n}=18)$

Work-related $(\mathrm{n}=19)$

Idiopathic $(n=104)$

Those with post-traumatic neck pain (mean age 43, sd 11.4, range 31-71) were significantly younger than those with idiopathic neck pain (mean age 52, sd 15.1, range 28-88; $\mathrm{P}<0.02$ ). Those with work-related neck pain (mean age 41, sd 11.3, range 23-60) were significantly younger than those with idiopathic neck pain $(\mathrm{P}=0.003)$. The total duration of pain was longer in the idiopathic group (mean 76, sd 93, range 1-530 months) than in post-traumatic (mean 45, sd 64, range 5-248 months). The episode duration of pain was longer in the idiopathic group (mean 17, sd 37, range 0-240 months) than in post-traumatic (mean 12, sd 8.8, range 1-26 months), but these differences were not significant. Similar non-significant differences in total and episode duration of pain were noted in the work-related compared to the idiopathic group. The idiopathic, post-traumatic and work-related groups all had a similar level of disability.

The female: male ratio was 1.8:1 for the whole group, but the post-traumatic sex ratio was 0.8:1. 
Frank et al: Neck pain and disability - proof check - 27-05-04

Analysis of place of birth revealed that 56 (40\%) were born in the UK. Those from other countries were East Africa 25 (18\%), the Indian subcontinent 23 (16\%), other European countries (including the Republic of Ireland) 12 (8\%), West Indies 11 (7.8\%), Middle East 7 (5\%) and 7 (5\%) from other countries altogether totalling 25 countries.

\section{Pain characteristics}

The mean duration of neck pain from the first ever experience was 5.8 (sd 7.3, range 0.1-44) years and the mean duration of the current attack of pain $(n=139)$ was 1.3 (sd 2.7, range $0.01-20$ ) years. One hundred and one subjects had chronic pain (73\%), 8 subjects had acute pain (6\%) of whom 3 had pre-existing neck pain. Thirty (22\%) subjects had subacute pain. Only 17 (12\%) were in pain at the onset of the current episode (acute/subacute on chronic pain), and two stated that they were pain free when they were seen. Those who were older had significantly longer duration of pain than those who were younger $(\mathrm{p}=0.024)$, but were not more disabled.

The majority 104 (74\%) had idiopathic neck pain. Eighteen (13\%) had trauma-related pain of which 16 (11\%) were due to road traffic accidents and $2(1 \%)$ other trauma. The remaining 19 (13\%) were possibly work-related (see Table 2).

Medical assessment found that pain was confined to the neck or trapezius areas in 27 (19\%); referred to the arms without neurological deficit in 94 (67\%); and had neurological deficit in 19 (13\%) patients, including one patient with confirmed root compression and 1 with cord compression. One patient was not classified as she 
described herself as 'pain-free', although she scored 1 on the NPQ 'I can do my usual work but it causes me extra pain'.

\section{Work status}

Of those of working age, the majority were employed and working $(n=61,43 \%)$ or self-employed and working ( $n=6,4 \%)$. Other subjects were retired $(n=30,21 \%)$, housewives ( $n=17,12 \%)$, employed but off sick ( $n=9,6 \%$ ), not working due to disabling spinal pain $(n=8,6 \%)$, unemployed $(n=6,4 \%)$, disabled from non-spinal conditions ( $\mathrm{n}=3,2 \%$ - failed hip surgery, dermatomyositis and partial blindness) and 1 subject was working reduced hours as part of a 'return to work' programme.

Excluding those retired and housewives, there were 94 potentially employable people, of which 67 (71\%) were working normally. Forty-four (47\%) individuals had taken sickness absence for neck pain at some time. Data on the duration were available from 42 (45\%) -17 men and 25 women. The mean sickness absence was 30 (sd 98, range 0.4-624) weeks (equivalent to 3.6 years of sickness absence in total).

\section{Comorbidities}

All subjects except $15(11 \%)$ reported 1 or more comorbidity. One third (n=42, 30\%) reported 1 comorbidity, a further one third (n=43, 31\%) reported 2 comorbidities, whilst 40 (29\%) reported 3 or more comorbidities. In all, comorbidities were reported 262 times. Lumbar pain was the most common ( $n=76,54 \%)$. The other comorbidities 
reported were thoracic pain ( $n=42,30 \%)$, peripheral joint arthritis $(n=33,24 \%)$, gastrointestinal diseases $(n=30,21 \%)$, cardiac disease $(n=21,15 \%)$, other musculoskeletal complaints ( $n=18,13 \%)$, thoracic diseases $(n=15,11 \%)$, and all other complaints numbered 27 (19\%). While 15 (11\%) subjects reported no comorbidity, only a further 17 subjects (12\%) had no musculoskeletal comorbidity.

Only 53 subjects (38\%) were given neck pain as a sole diagnosis made by the clinicians. Additional diagnoses made in clinic are shown in Table 3, and included low back pain (26\%), spinal deformity (10\%), and clinical depression (9\%). Four percent had previous spinal surgery.

\section{Disability (as measured with the NPQ)}

The NPQ was completed by 132 subjects. The mean disability score excluding driving (maximum possible score 32), was 14 (Table 4) with no difference between the sexes. The driving question was completed by 90 subjects ( 34 women). The mean scores on all NPQ items are given in Table 5. There were 42 non-drivers of which 34 were women. A comparison of the non-drivers with those who did drive showed that the non-drivers were significantly older (mean age 58) than the drivers - (mean age 46, $\mathrm{p}<0.0001)$

Subjects aged 50 or less ( $n=75$ ) were not significantly less disabled than those aged 51 and over ( $n=57)$. Younger men were more disabled than older men (Table 4). There were no differences in NPQ between older and younger women. There were no significant relationships between the NPQ and:- route of referral, cause of disability, 
clinical pattern, episode \& total duration of pain and social class. Data on NPQ and country of birth are given in Table 4 but there were no significant differences.

\section{Relationships between work status and disability}

These relationships are given in Table 4 and show the highest disability score was found in those who were not working through disability and the lowest in those who were self-employed and able to work. Those in work $(n=63)$ were significantly less disabled than those not working $(n=22, p=0.001)$ and those 'off sick now' $(n=9$, $\mathrm{p}<0.01)$

Nineteen subjects were thought to have potentially work-related pain. The main features at work thought to aggravate the neck pain are given in Table 2. These 19 individuals represent $16 \%$ of those aged 64 or less (or $18 \%$ excluding housewives).

\section{Comorbidity}

There was a significant relationship between the increasing number of comorbidities and worsening disability (Table 4). Those with musculoskeletal comorbidities were not significantly more disabled than those without. However those with low back pain were significantly more disabled on the NPQ than those without $(\mathrm{P}=0.017)$.

\section{Sleep and tearfulness}


Frank et al: Neck pain and disability - proof check - 27-05-04

Sleep was disturbed by pain in 104 (75\%) patients for whom answers were given ( $n=139)$. When asked about other factors that disturbed sleep, 56 of the 137 respondees (41\%) reported other symptoms. Of these 16 (12\%) probably reflected other systemic problems (nocturia reported by 10 patients), the spinal nature of the problems (10 patients) whilst other symptoms may reflect possible psychological factors (9 patients). Individuals whose sleep was disturbed by pain were significantly more disabled than those without sleep disturbance (Table 4).

Eighty-three of 139 respondents (60\%) admitted that the pain made them feel tearful, and 58 (42\%) reported that the pain made them cry. Those who cried were significantly more disabled than those who did not (Table 4). Those who felt tearful were also significantly more disabled than those who did not.

Comparisons between this cohort and a similar cohort of patients reported in this journal with low back pain (17) are shown in Table 6. The age and sex distributions are remarkably similar. Conversely those presenting with neck pain present earlier then those presenting with back pain and appear to have a much greater musculoskeletal comorbidity. In spite of this the proportion of working age receiving benefits was much smaller. 


\section{DISCUSSION}

This study has reported the diversity of patients presenting with neck pain to a rheumatology outpatient service, characterised by the range of symptom presentation, and the impact of the functional, emotional and work handicap experienced. Neck pain is not a diagnosis in itself, but is a presentation of symptoms and signs around the neck region, ${ }^{14}$ often occurring with pain reported at other sites. ${ }^{6}$ As with low back pain, it is thought to be multidimensional. In this study, neck pain as the sole symptom was seen in a minority of patients. Thus the picture of neck pain referred to secondary care is complex.

Although several studies have emphasised the importance of assessing disability in neck pain patients, ${ }^{9,22}$ and is appreciated as an outcome measure for neck pain, few studies have described the nature of the neck-related disability. This study is the first, to our knowledge, to characterise neck pain and its consequences, including an exploration of the potential contribution of neck pain to sickness absence, in an UK secondary care sample.

\section{The sample}

Nearly one in five patients had conditions other than mechanical or degenerative neck pain (Table 1). The commonest reason was pain arising from other sites in the spine (5\%). This is similar to the patients seen in a low back pain clinic when $8 \%$ had pain arising from the thoracic and cervical spine (Table 6). ${ }^{17}$ Tumours presenting as pain in 
the neck were rare $(n=1,0.6 \%)$ and similar to that reported from a low back pain clinic (0.5\%). ${ }^{17}$

One patient presenting with neck pain was found to have Parkinson's Disease. This presentation has not been noted previously to our knowledge, although neck pain is not uncommon in Parkinson's Disease. Neither has it been noted in major reviews of neck pain. ${ }^{1,23,24}$

Postcode analysis showed that $99 \%$ of the sample lived locally, indicating that this suburban general hospital service provides for its local population.

\section{Clinical characteristics}

The majority of patients were found to have pain referred to the arms and a small number had a neurological deficit. These two groups accounted for $80 \%$ of the study population, as expected in view of the tendency of radiating neck pain to persist. ${ }^{25}$ Referred symptoms to the arms or hands may be more problematic to patients as sensation in the arms is functionally important e.g. giving rise to dropping things, while sensory impairment in the legs may be tolerable. This may also explain why those presenting with neck pain do so earlier than those with low back pain (Table 6).

The proportion of patients with neck pain and comorbidity was substantially higher than that in a back pain cohort and the proportion with musculo-skeletal comorbidity was over twice as high (Table 6). ${ }^{17}$ This has also been noted in a cohort of female 
workers. ${ }^{26}$ Thus those referred to secondary care with neck pain need a holistic assessment to obtain the full clinical picture.

Only a small proportion of post-traumatic neck pain, mostly road traffic accidents was found in this sample. Bogduk has noted that neck pain resulting from whiplash has its own literature that is almost quarantined from that on neck pain. ${ }^{1}$ Whereas the classification of whiplash-associated disorders has been used in practice, ${ }^{27}$ similar attempts in non-specific neck pain are not readily found ${ }^{28}$ although Borenstein and colleagues have a useful approach to diagnosis and management. ${ }^{14}$ This clinic triaged patients into 3 groups for therapeutic purposes. This approach is similar to others ${ }^{29,30}$ and follows the model used for low back pain including the use of red flags. ${ }^{31}$ Those practising manual treatments may use more complex classifications. ${ }^{32}$

Excluding 9 patients with spinal pain from other sites and 1 pain free, our triage revealed 23 patients with other conditions (14\%). Nineteen patients had nerve involvement (11\%) and 121 had neck/arm pain (without neurological involvement 70\%). This triage appears as useful as that used for low back pain.

We have found it helpful to group mechanical or degenerative neck disorders into idiopathic (74\%), probably work-related (13\%) and traumatic (13\%) groups. Trauma should be a 'red flag, ${ }^{31}$ for neck pain as we found a missed fracture and psychological morbidity (Table 1). The psychological consequences of trauma are common, ${ }^{33}$ neglected in practice and complex to evaluate. 
Although nearly half of the patients had taken sickness absence for neck pain, only $12 \%$ were unable to work because of neck-related pain when seen in clinic. This is reflected in the relatively low levels of disability reported, and is similar to the $13 \%$ noted by Kamwendo et al. ${ }^{34}$ Nonetheless the total amount of sickness absence (3.6 years) reported in this cohort has important economic implications, as noted in Holland. ${ }^{35}$

In this study, only a small number were found to have work-related neck pain. These conditions are important and affect management. It is recognised that neck and arm pain may not be caused by work; ${ }^{2,36-40}$ but that clinical management requires evaluation of working practice. ${ }^{11,41}$ Posture is thought to be important in the context of work. ${ }^{34}$ Both ergonomics and the employer's working practices may need modification, particularly if sickness absence has resulted or when repetitive work, or working with static postures is involved. ${ }^{28,34,41}$

\section{Symptom duration}

Duration of symptoms from the first episode of neck pain was nearly 6 years, less than for low back pain (Table 6), ${ }^{17}$ but much less than the neck pain group studied by Wlodyka-Demaille et al. ${ }^{20}$ The episode duration, just over 1 year, was much less than that for low back pain, ${ }^{17}$ but more than the French study. ${ }^{20}$

This symptom duration may justify referral to a multiprofessional rehabilitation programme as described by Pither ${ }^{42}$ where available, when other treatments have been 
unsuccessful. Not all general practitioners had open access referral to physiotherapists at the time of this study as is now recommended. ${ }^{8}$

\section{Ethnicity}

The Rheumatology Service receives referrals from North West London, which is an area of ethnic diversity. Our data confirm the diversity of ethnicity in terms of country of origin in North West London. In general, South Asian patients experience significantly worse low back pain than British-born patients. In addition, Muslims consistently reported the worst experience of low back pain compared to all other religious groups. ${ }^{15}$ Ethnic influences on the experience of pain have been found in the United States ${ }^{43}$ although they were not clearly related to medical status. ${ }^{44}$ Our results (not shown) are in keeping with previous data suggesting that Muslims may experience pain more severely than other religious groups. ${ }^{15}$ Our findings did not reach statistical significance, probably due to small numbers. Further work is needed to elucidate whether such findings, if replicated, may reflect work / leisure activities or purely psychological influences.

\section{Comorbidity}

A high degree of comorbidity was found in this study, particularly musculoskeletal comorbidity due to the large number of patients with low back pain (54\%). This degree of comorbidity was not reflected in the working clinical diagnosis reported back to the general practitioner after consultation. However the finding agrees with Kamwendo et $\mathrm{al}^{34}$ who found $51 \%$ of medical secretaries with neck and shoulder 
disorders also had back pain. We recommend that all patients with neck pain are asked about other spinal sites of pain. We have also reported the high incidence of neck pain in a cohort of patients with low back pain (24\%) of almost identical age. ${ }^{17}$ All patients presenting with either low back or neck pain should have the whole spine examined in order to give appropriate advice or therapy.

There are considerable implications for rehabilitating patients back into employment if both lumbar and cervical areas of the spine are involved. ${ }^{11}$ Whether the presence of both lumbar and cervical problems reflect congenital factors e.g. narrow spinal canal diameter or a predisposition to discal degeneration or to lifestyle or work factors needs further exploration. This data supports the view that "the spine should be considered a functional unit”. ${ }^{45}$

\section{Disability}

Of the functional items on the NPQ, limitations in carrying were found to be the most reported (Table 5). This may reflect the fact that carrying is an upper limb function and often related to clerical activities e.g. taking papers to school or work, carrying portable computers etc. It may indicate traction on the neck and brachial plexus. Social activities and driving were the least reported, although almost one third of the sample were not drivers (in contrast to the $5 \%$ noted by Wlodyka-Demaille et al. ${ }^{20}$ )

We analysed the NPQ driving question separately and found that, of those unable to drive, the majority were elderly women. This item may not be appropriate for inclusion in a questionnaire used in a general spinal clinic population with no age 
limits. The high levels of comorbidity in this population may limit the value of questionnaires specifically designed for neck pain. Consideration should be given to the use of more generic questionnaires e.g. the Aberdeen Questionnaire. ${ }^{45}$ The NPQ does not explore the emotional dimension ${ }^{21}$ but is straightforward to use in a multicultural environment including elderly individuals. In this study 132 (94\%) subjects completed the NPQ.

\section{Sleep}

Individuals with sleep disturbance were significantly more disabled than those without. Improving sleep may result in a reduction of a patient's suffering. ${ }^{46}$ The fact that many wake with neck pain and stiffness should point clinicians to unsatisfactory pillows or sleeping position. There is evidence that pillows are important to patients' ${ }^{47}$ Those that offer firm support for the neck $\operatorname{lordos}^{47}$ seem preferable. Alternatively, or in addition, long-acting analgesics may be helpful.

The 16 subjects with sleep disturbed by systemic symptoms reflect the fact that there was considerable comorbidity compounding their neck problems. Although only a small proportion of the sample, they need to have the cause of their insomnia managed.

\section{Tearfulness and crying}

Our findings demonstrated that those who were tearful and reported crying because of their neck pain were significantly more disabled than those who were not. Workplace 
stress $^{2,25,48}$ and other psychological factors are known to influence the experience of neck pain and may aggravate pain through increased tension in the trapezei. Those with clearly identified psychological distress need appropriate management e.g. antidepressant therapy or psychological support. Such individuals may be better managed in a multidisciplinary rehabilitation programme. ${ }^{49}$

\section{Weaknesses of the study}

We made no formal assessment of hypermobility although this could potentially predispose to neck pain related either to trauma or repetitive movements. We made no formal assessment of mood. Previous studies had shown low compliance with standard assessment tools ${ }^{17}$ and questioned the cross-cultural validity of some commonly used psychometric scales ${ }^{15}$. Although country of birth is not a reliable proxy for ethnic background, the diversity of places of birth shows the need for sensitivities on the part of clinicians investigating possible psychosocial dimensions to the experience of pain.

Additionally, no extra help was available to assist patients in the completion of their questionnaires. The data was collected as part of a routine NHS clinic without additional time for extended assessment or examination, and therefore reflects the clinical reality of this secondary care rheumatology service in a suburban district general hospital serving the local population. 
Frank et al: Neck pain and disability - proof check - 27-05-04

\section{Conclusion}

This study illustrates that neck pain presenting to an outpatient clinic is complex and usually associated with both physical and psychological comorbidity. An approach to the management of neck pain using a biopsychosocial model of care ${ }^{50}$ facilitates a focus on the individual as a whole where neck pain is one important component of their presentation. With this in mind we have not focussed on the concept of fibromyalgia as we, in agreement with current opinion, ${ }^{51-54}$ have found that investigating tender points does not advance patient management.

Comprehensive management of neck pain requires a biopsychosocial model of care that includes recognising features related to trauma or to lifestyle, including work.

This study suggests that there are considerable economic costs in terms of sickness absence from neck pain, which would appear to justify further research into this neglected area.

\section{Acknowledgements}

Aisha Shah for help with original analysis and Dr Pat Thrower for assistance in collecting the data. 
Frank et al: Neck pain and disability - proof check - 27-05-04

\section{References}

1. Bogduk N. The neck. Best Pract Res Clin Rheumatol 1999; 13: 261-285

2. Palmer KT, Walker-Bone K, Griffin MJ et al. Prevalence and occupational associations of neck pain in the British population. Scandinavian Journal of Work, Environment \& Health 2001; 27: 49-56

3. Ariëns GAM, Borghouts J, Koes BW. Neck pain. In Crombie IK, Croft PR, Linton SJ, LeResche L, Von Korff M (eds) Epidemiology of pain. Seattle: IASP Press, 2003; 235-255

4. Croft PR, Lewis M, Papageorgiou AC et al. Risk factors for neck pain: a longitudinal study in the general population. Pain 2001; 93: 317-325

5. Cote P, Cassidy JD, Carroll L. The Saskatchewan Health and Back Pain Survey. The prevalence of neck pain and related disability in Saskatchewan adults. Spine 1998; 23: 1689-1698

6. Picavet H, Schouten J. Musculoskeletal pain in the Netherlands: prevalences, consequences and risk groups, the DMC3 study. Pain 2003; 102: 167-178

7. Gore DR, Sepic SB, Gardner GM, Murray MP. Neck Pain: a long-term follow up of 205 patients. Spine 1987; 12: 1-5

8. Philadelphia Panel. Philadelphia Panel evidence-based clinical practice guidelines on selected rehabilitation interventions for neck pain. Phys Ther 2001; 81: 1701-1717

9. Wheeler AH, Goolkasian P, Baird AC, Darden BV. Development of the Neck Pain and Disability Scale. Item analysis, face, and criterion-related validity. Spine 1999; 24: 1290-1294

10. van der Windt D, Croft P, Penninx B. Neck and upper limb pain: more pain is associated with psychological distress and consultation rate in primary care. J Rheumatol 2002; 29: 564-569

11. Hartigan C, Miller L, Liewehr SC. Rehabilitation of acute and subacute low back and neck pain in the work-injured patient. Orthop Clin North Am 1996; 27: 841-860 
Frank et al: Neck pain and disability - proof check - 27-05-04

12. Department for Work and Pensions. Pathways to work: helping people into employment. Cm 5690, 2002: 1-65

13. Chartered Institute of Personnel and Development. Employee absence 2002: a survey of management policy and practice. London: Chartered Institute of Personnel and Development. 2002: $1-21$

14. Borenstein DG, Wiesel SW, Boden SD. A standardised approach to the diagnosis and management of neck pain. In Borenstein DG, Wiesel SW, Boden SD (eds). Neck pain. Medical diagnosis and comprehensive management. Philadelphia: W.B. Saunders Co, 1996: 140-162.

15. McAuley, JH. Cultural influences on low back pain: extending the biopsychosocial model. PhD Thesis, Brunel University, 2001: 1-208

16. Office of Population Census and Surveys. Standard Occupational Classification. London: HMSO, 1990.

17. Frank AO, De Souza LH, McAuley JH et al. A cross-sectional survey of the clinical and psychological features of low back pain and consequent work handicap: use of the Quebec Task Force Classification. Int J Clin Pract 2000; 54: 639-644

18. Spitzer WO, LeBlanc FE, Dupuis M. Scientific approach to the assessment and management of activity-related spinal disorders. A monograph for clinicians. Spine 1987; 12: S1-S59

19. Leak AM, Cooper J, Dyer S et al. The Northwick Park Neck Pain Questionnaire devised to measure neck pain and disability. Br J Rheumatol 1994; 33: 469-474

20. Wlodyka-Demaille S, Poiraudeau S, Catanzariti JF et al. French translation and validation of 3 functional disability scales for neck pain. Arch Phys Med Rehabil 2002; 83: 376-382

21. Hoving JL, O'Leary EF, Niere KR et al. Validity of the neck disability index, Northwick Park neck pain questionnaire, and problem elicitation technique for measuring disability associated with whiplash-associated disorders. Pain 2003; 102: 273-281 
Frank et al: Neck pain and disability - proof check - 27-05-04

22. Wlodyka-Demaille S, Poiraudeau S, Fermanian J et al. French translation and validation of a functional disability scale for neck pain. Ann Readaptation Med Phys 2002; 44: 132-142

23. Barry M, Jenner JR. Pain in neck, shoulder, and arm. BMJ 1995; 310: 183-186

24. Borenstein DG, Weisel SW, Boden SC. Neck pain. Medical diagnosis and comprehensive management. Philadelphia: W.B. Saunders Company, 1996

25. Viikari-Juntura E, Martikainen R, Luukkonen R et al. Longitudinal study on work related and individual risk factors affecting radiating neck pain. Occup Environ Med 2001; 58: 345-352

26. Makela M, Heliovaara M, Sievers K et al. Prevalence, determinants, and consequences of chronic neck pain in Finland. Am J Epid 1991; 134: 1356-1367

27. Hartling L, Brison RJ, Ardem C, Pickett W. Prognostic value of the Quebec Classification of Whiplash-associated disorders. Spine 2001; 26: 36-41

28. Nordin M, Pietrek M, Halpern M. ( Combination treatment for non-specific neck pain. In Szpalski M, Gunzberg R (eds). The degenerative cervical spine. Philadelphia: Lippincott, Williams \& Wilkins, 2001: 137-142.

29. Tsang I. Rheumatology: 12. Pain in the neck. Can Med Assoc J 2001; 164: 1182-1187

30. Greenough CG. Diagnosis and treatment in evidence-based healthcare systems. In Szpalski M, Gunzberg R (eds) The degenerative cervical spine. Philadelphia: Lippincott, Williams \& Wilkins, 2001: 319-325

31. Clinical Standards Advisory Group (Chairman Prof. M Rosen). Back Pain. London: HMSO. 1994: 1-89

32. McClure P. The degenerative cervical spine: pathogenesis and rehabilitation concepts. [Review]. J Hand Ther 2000; 13: 163-174

33. Mayou R, Bryant B, Duthie R. Psychiatric consequences of road traffic accidents. BMJ 1993; 307: 647-651 
Frank et al: Neck pain and disability - proof check - 27-05-04

34. Kamwendo K, Linton SJ, Moritz U. Neck and shoulder disorders in medical secretaries. Part 1. Pain prevalence and risk factors. Scand J Rehab Med 1991; 23: 127-133

35. Borghouts J, Koes BW, Vondeling H, Bouter LM. Cost of illness of neck pain in The Netherlands in 1996. Pain 1999; 80: 629-636

36. Helliwell PS. Diagnostic criteria for work-related upper limb disorders. Br J Rheumatol 1996; 35: $1195-1196$

37. Barton NJ, Hooper G, Noble J, Steel WM. Occupational causes of disorders in the upper limb. BMJ 1992; 304: 309-311

38. Coggon D, Palmer KT, Walker-Bone K. Occupation and upper limb disorders. Rheumatol 2000; 39: 1057-1059

39. British Society of Rehabilitation Medicine. Vocational Rehabilitation: the way forward (Chair Frank AO), 2nd edn. London: British Society of Rehabilitation Medicine, 2003

40. Macfarlane GJ, Hunt IM, Silman AJ. Role of mechanical and psychosocial factors in the onset of forearm pain: prospective population based study. BMJ 2000; 321: 676-679

41. Mclean L, Tingley M, Scott RN, Rickards J. Computer terminal work and the benefit of microbreaks. Appl Ergonomics 2001; 32: 225-237

42. Pither CE. Pain clinic. In Szpalski M, Gunzberg R (eds) The degenerative cervical spine, Philadelphia: Lippincott, Williams \& Wilkins, 2001: 161-173

43. Riley JL, Wade JB, Myers CD et al. Racial/ethnic differences in the experience of chronic pain. Pain 2002; 100: 291-298

44. Edwards C, Keefe F. New directions in research on pain and ethnicity: a comment on Riley, Wade, Myers et al. Pain 2002; 100: 211-212 
Frank et al: Neck pain and disability - proof check - 27-05-04

45. Williams NH, Wilkinson C, Russell IT. Extending the Aberdeen back pain scale to include the whole spine: a set of outcome measures for the neck, upper and lower back. Pain 2001; 94: 261274

46. McCracken LM, Iverson GL. Disrupted sleep patterns and daily functioning in patients with chronic pain. Pain Res \& Management 2002; 7: 75-79

47. Ambrogio N, Cuttiford J, Lineker S, Li L. A comparison of three types of neck support in fibromyalgia patients. Arthritis Care Res 1998; 11: 405-410

48. Vasseljen O, Holte KAW, Westgaard RH. Shoulder and neck complaints in customer relations: individual risk factors and perceived exposures at work. Ergonomics 2001; 44: 355-372

49. Persson LCG, Lilja A. Pain, coping, emotional state and physical function in patients with chronic radicular neck pain. A comparison between patients treated with surgery, physiotherapy or neck collar - a blinded, prospective randomised study. Disabil Rehabil 2001; 23: 325-335

50. Waddell G. A new clinical model for the treatment of low back pain. 1987 Volvo award in clinical sciences. Spine 1987; 12: 632-644

51. Croft P. Symptoms without pathology: should we try a little tenderness? Rheumatol 2003; 42: 815-817

52. Hazemeijer I, Rasker JJ. Fibromyalgia and the therapeutic domain. A philosophical study on the origins of fibromyalgia in a specific social setting. Rheumatol 2003; 42: 507-15

53. Schochat T, Raspe H. Elements of fibromyalgia in an open population. Rheumatol 2003; 42: 829-35.

54. Quintner JL, Cohen ML. Fibromyalgia falls fowl of a fallacy. Lancet 1999; 353: 1092-4. 


\section{Table 1}

\section{Other conditions presenting to a neck pain clinic $(n=32)$}

\section{Other sites of spinal pain $(\mathbf{n}=9)$}

$\begin{array}{lr}\text { Lumbar pain } & 6\end{array}$

$\begin{array}{ll}\text { Thoracic pain } & 3\end{array}$

Shoulder pain $(\mathbf{n}=8)$

$\begin{array}{lr}\text { Idiopathic shoulder pain } & 6\end{array}$

Wheelchair-dependent athlete with a ventriculo-peritoneal shunt 1

Carpal tunnel syndrome and shoulder pain $\quad 1$

Conditions mimicking neck symptoms $(n=6)$

$\begin{array}{ll}\text { Giddiness ? Cause } & 1\end{array}$

$\begin{array}{ll}\text { Labyrinthitis } & 1\end{array}$

$\begin{array}{ll}\text { Menieres disease } & 1\end{array}$

$\begin{array}{ll}\text { Parkinson's disease } & 1\end{array}$

$\begin{array}{lr}\text { Pulsatile tinnitus } & 1\end{array}$

$\begin{array}{ll}\text { Raynaud's phenomenon } & 1\end{array}$

Neck pain due to other primary conditions $(n=5)$ 
Frank et al: Neck pain and disability - proof check - 27-05-04

$\begin{array}{ll}\text { Depression } & 1\end{array}$

$\begin{array}{ll}\text { Lymphoma compressing cord } & 1\end{array}$

$\begin{array}{ll}\text { Rheumatoid arthritis } & 1\end{array}$

$\begin{array}{lr}\text { Fractured C1 vertebra } & 1\end{array}$

$\begin{array}{lr}\text { Spasmodic torticollis } & 1\end{array}$

$\begin{array}{ll}\text { Carpal tunnel syndrome }(\mathbf{n}=4) & 4\end{array}$

$\begin{array}{ll}\text { TOTAL } & 32\end{array}$ 


\section{Table 2}

\section{Work thought to be partly responsible for neck pain $(n=19)$}

\section{Sitting $\mathbf{n}=\mathbf{1 0}$}

Computer consultant

$\mathrm{P} / \mathrm{T}$ receptionist in retail chemist

Building society clerk

Health promotion administrator

VDU operator (typing and graphics)

Typist

Sewing machinist

Checkout worker (and packer)

Driver - part-time Meals-on-Wheels driver (includes delivery and cleaning)

Driver - bus driver

\section{Standing $n=5$}

Sales assistant

Dental technician

Laboratory technician

Display assistant

Hairdresser

\section{Lifting $n=3$}

Assembly line worker - lifts 5-25 litre drums on a production line 
Frank et al: Neck pain and disability - proof check - 27-05-04

Dark room worker - stands all the time \& lifts up to 40 lbs. repetitively

District Nurse

\section{Other $n=1$}

Electronic Engineer 


\section{Table 3}

\section{Additional diagnoses noted in clinic}

\section{$\underline{\text { Additional diagnosis * }}$}

$\underline{\text { No. }(n=141)} \quad \underline{\%}$

\section{Musculoskeletal}

Low back pain $\quad 36$

Spinal deformity

Osteoarthritis of the lower limbs

Shoulder pain

06

04

Thoracic pain

06

Previous spinal surgery

05

Osteoarthritis of the upper limbs

04

03

Carpal tunnel syndrome

03

02

Osteoporosis

03

02

Repetitive strain injury (probable)

02

01

Vertebro-basilar insufficiency

02

01

Other musculo-skeletal

07

05

\section{Other diagnostic groups}

Depression / anxiety

Diabetes mellitus

Asthma

Cardiovascular 
Frank et al: Neck pain and disability - proof check - 27-05-04

Other

Gastro-intestinal

Neck pain only
05

03

02
04

* Some individuals had more than 1 diagnosis

53

38 


\section{Table 4}

Clinical and demographic relationships with disability

(NPQ excluding driving)

\begin{tabular}{|c|c|c|c|c|c|}
\hline Variable & $\mathbf{N}$ & Mean NPQ & Range & SD & Significance \\
\hline All patients & 132 & 14 & $1-32$ & 6.5 & \\
\hline Men aged 0-50 & 75 & 10.7 & $1-20$ & 5.9 & \\
\hline Men aged 51+ & 57 & 17.3 & $4-32$ & 7.3 & \\
\hline \multicolumn{6}{|l|}{ Country of birth } \\
\hline Other European & 10 & 11.5 & $3-21$ & 6.4 & \\
\hline Other & 6 & 13.0 & $1-21$ & 6.7 & \\
\hline UK & 54 & 13.5 & $1-28$ & 5.9 & \\
\hline Middle East & 7 & 13.8 & $1-22$ & 8.6 & \\
\hline West Indies & 10 & 14.2 & $7-25$ & 5.8 & \\
\hline South Asia & 45 & 15.2 & $1-32$ & 7.0 & \\
\hline \multicolumn{6}{|l|}{ Work status } \\
\hline $\begin{array}{l}\text { Not working through } \\
\text { disability }\end{array}$ & 7 & 19.4 & $11-25$ & 5.8 & $\mathrm{P}=0.001^{2}$ \\
\hline Housewives & 12 & 18.4 & $9-23$ & 4.1 & \\
\hline Employed but off sick & 9 & 18.2 & $5-32$ & 7.1 & $\mathrm{P}<0.01^{2}$ \\
\hline
\end{tabular}




\begin{tabular}{|c|c|c|c|c|c|}
\hline Retired & 31 & 13.7 & $3-28$ & 6.9 & \\
\hline Unemployed & 6 & 13.7 & $10-16$ & 2.6 & \\
\hline Employed and working & 57 & 12.1 & $1-23$ & 5.7 & \\
\hline Self-employed & 6 & 9.3 & $1-19$ & 7.6 & \\
\hline & & & & & \\
\hline \multicolumn{6}{|l|}{ Comorbidities } \\
\hline & & & & & \\
\hline No comorbidity & 14 & 10.2 & $1-21$ & 7.2 & \multirow{4}{*}{$\mathrm{P}=0.004^{1}$} \\
\hline 1 comorbidity & 40 & 12.6 & $1-26$ & 6.3 & \\
\hline 2 comorbidities & 41 & 14.7 & $1-23$ & 5.6 & \\
\hline $3+$ comorbidities & 36 & 16.1 & $3-32$ & 6.7 & \\
\hline Unknown & 1 & 16.0 & & & \\
\hline Comorbidity - low back pain & 72 & 15.4 & $1-32$ & 5.8 & $\mathrm{P}=0.017^{2}$ \\
\hline Sleep disturbed & 99 & 15.7 & & 5.8 & \multirow{2}{*}{$\mathrm{P}=0.0001^{2}$} \\
\hline Sleep not disturbed & 33 & 8.8 & & 5.7 & \\
\hline Crying & 52 & 17.4 & & 5.1 & \multirow[t]{2}{*}{$\mathrm{P}=0.0001^{2}$} \\
\hline Not crying & 78 & 11.7 & & 6.3 & \\
\hline Felt tearful & 77 & 16.6 & & 5.2 & \multirow[t]{2}{*}{$\mathrm{P}=0.0001^{2}$} \\
\hline Not feel tearful & 53 & 10.2 & & 6.2 & \\
\hline
\end{tabular}

Key: ${ }^{1}$ Spearman’s Rank Correlation Coefficient, ${ }^{2}$ Mann Whitney 


\section{Table 5}

\section{Means of NPQ * individual questions 1-9}

( $n=132$ except for driving)

$\begin{array}{lccc} & \text { Mean } & \text { sd } & \text { Range } \\ \text { Neck pain intensity } & 1.7 & 1.0 & 0-4 \\ \text { Neck pain and sleeping } & 1.7 & 1.1 & 0-4 \\ \text { Pins and Needles or numbness in the arms at night } & 1.3 & 1.0 & 0-4 \\ \text { Duration of Symptoms } & 2.8 & 1.3 & 0-4 \\ \text { Carrying } & 2.0 & 1.1 & 0-4 \\ \text { Reading and watching TV } & 1.6 & 1.0 & 0-4 \\ \text { Working / Housework etc. } & 1.6 & 1.2 & 0-4 \\ \text { Social activities } & 1.4 & 1.1 & 0-4 \\ \text { Driving (n=90) } & 1.4 & 1.1 & 0-4 \\ & & & \end{array}$




\section{Table 6}

\section{Comparison of patient characteristics between back and neck studies}

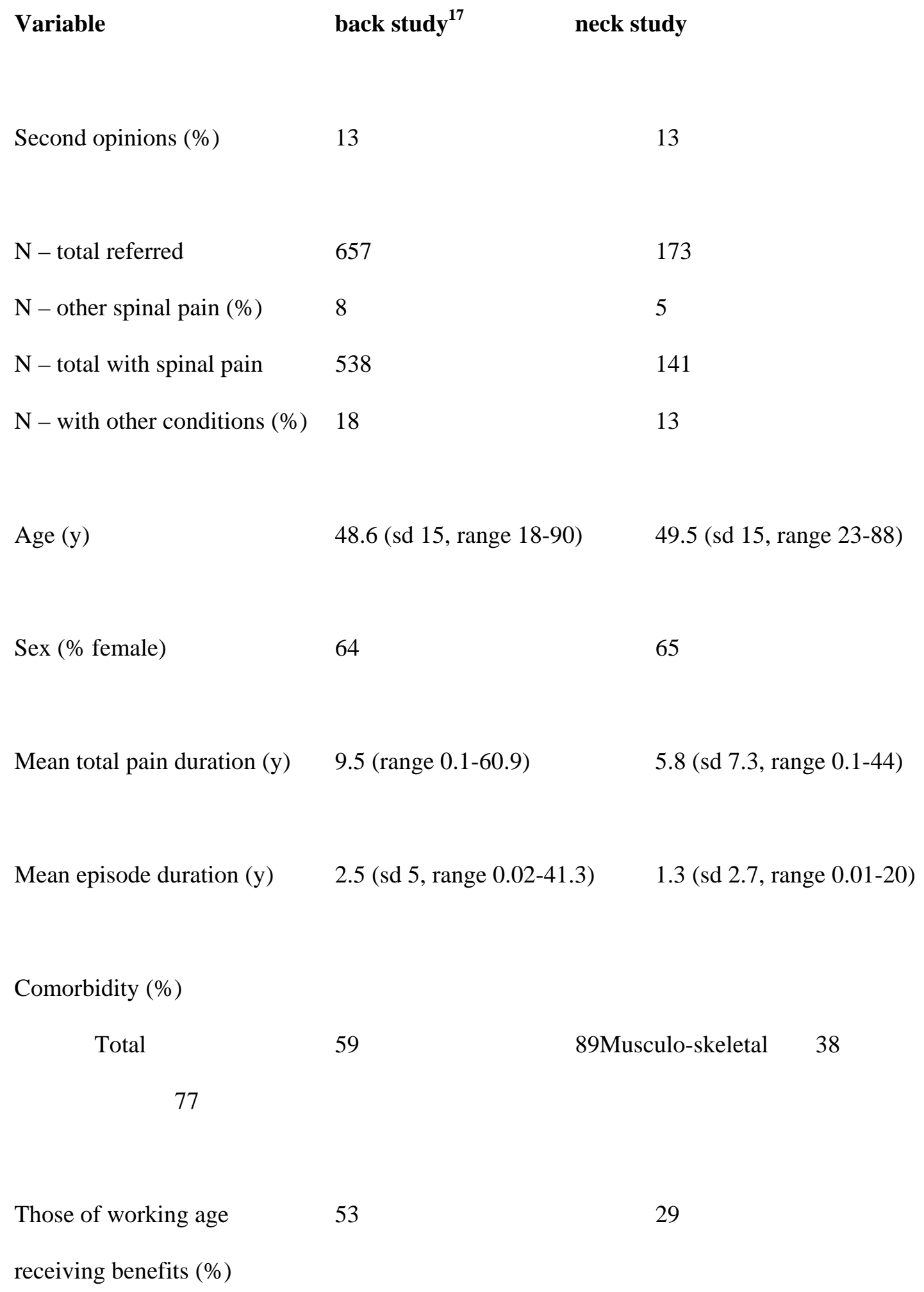


Frank et al: Neck pain and disability - proof check - 27-05-04

$\%$ with referred pain

75

81

(to limb) 
Frank et al: Neck pain and disability - proof check - 27-05-04

\section{Appendix 1}

\section{Neck pain clinic proforma}

\section{Comorbidity}

Thoracic pain

Low back pain

Peripheral joint arthritis

Other musculoskeletal

Cardiac

Respiratory

Gastro-intestinal

Other(s)

Sites of pain

Bilat symmetrical LBP

Refers to 1 or both buttocks

" " laterally- hip, iliac crest

Dorsi-lumbar pain

Lower thoracic pain

Mid-thoracic

Shoulders or trapezei

Neck

Refers leg - typical

Refers leg - atypical 
Frank et al: Neck pain and disability - proof check - 27-05-04

\section{Sites of pain}

1. Bilat symmetrical LBP

2. Refers to 1 or both buttocks

3. " " laterally- hip, iliac crest

4. Dorsi-lumbar pain

5. Lower thoracic pain

6. Mid-thoracic

7. Shoulders or trapezei

8. Neck

9. Refers leg - typical

10 Refers leg - atypical

Sleep

Is your sleep disturbed by pain?

Does anything else disturb sleep?

\section{Does the pain}

Ever make you feel tearful?

Ever make you cry

Does anything else make you cry? 